\title{
Platelet-dependent thrombography gives a distinct pattern of in vitro thrombin generation after surgery with cardio-pulmonary bypass: potential implications
}

Rose Said ${ }^{1,2+}$, Véronique Regnault ${ }^{1,2+}$, Marie Hacquard ${ }^{1,3}$, Jean-Pierre Carteaux ${ }^{1}$ and Thomas Lecompte ${ }^{1,2,3,4^{*}}$

\begin{abstract}
Background: Bleeding remains a potentially lethal complication of cardio-pulmonary bypass (CPB) surgery. The purpose of this study was to obtain a better insight into in vitro thrombin generation in the context of CPB.

Methods: We used Calibrated Automated Thrombography to assess blood coagulation of 10 low-risk patients operated for valve replacement with CPB, under 2 experimental conditions, one implicating platelets as platelet dysfunction has been described to occur during CPB.

Results: Our main finding was that CPB-induced coagulopathy was differently appreciated depending on the presence or absence of platelets: the decrease in thrombin generation was much less pronounced in their presence (mean endogenous thrombin potential change values before and after CPB were $-3.9 \%$ in the presence of platelets and $-39.6 \%$ in their absence).
\end{abstract}

Conclusion: Our results show that experimental conditions have a profound effect in the study of in vitro thrombin generation in the context of CPB.

Keywords: Cardio pulmonary bypass, Thrombin, Platelets, Thrombography

\section{Introduction}

Bleeding remains a feared complication of cardiopulmonary bypass $(\mathrm{CPB})$ surgery. Despite improvements, blood coagulation is still altered in the extracorporeal circuit [1-4]. We have reported in variant haemophiliacs that Calibrated Automated Thrombography (CAT), as an integrative in vitro phenotyping of coagulation, would be a better laboratory approach to assess the bleeding risk than the assays currently used in laboratory medicine [5]. Recent works have studied CAT thrombin generation in plasma of patients after CPB. Schols et al. [6] showed a decrease in thrombin generation associated with a decrease in fibrin formation (assessed with thromboelastography). In addition, Solomon et al [7]

\footnotetext{
* Correspondence: ThomasPierre.Lecompte@hcuge.ch

${ }^{\dagger}$ Equal contributors

'Laboratoire d'Hématologie et Institut Cardiovasculaire Nancy, Centre Hospitalier Universitaire, Nancy, France

2Inserm U961, Nancy Université, Nancy, France

Full list of author information is available at the end of the article
}

have shown that fibrin formation is more altered than thrombin generation following CPB. Furthermore, Coakley et al. [8] have shown a correlation between preand post-operative Endogenous Thrombin Potentials (ETP), and more importantly an association with bleeding complications, suggesting that this assay is informative in this context [5]. CAT can be performed in the presence of platelets [9]. To obtain a better insight into in vitro thrombin generation in the context of $\mathrm{CPB}$, we used CAT under 2 experimental conditions, one implicating platelets. To the best of our knowledge this has never been performed with CAT in the context of CPB.

\section{Materials and methods Patient population}

Ten low-risk adult patients scheduled for replacement of one heart valve ( 6 aortic, 4 mitral) included. There were 7 men and 3 women; 70 years (59-87) of age (continuous variables are expressed as medians and ranges). All 
patients signed an informed consent form approved by the local research committee.

\section{Collection of blood samples}

Venous blood samples were collected before CPB and shortly after protamine injection into S-Monovette ${ }^{\circledR}$ tubes (Sarstedt) containing 0.109 M citrate, in the proportion of 1 volume citrate to 9 volumes of blood. PlateletRich Plasma (PRP) was prepared by blood centrifugation at $190 \mathrm{~g}$ for $10 \mathrm{~min}$ at $20^{\circ} \mathrm{C}$. The PRP was recovered and adjusted to $150 \mathrm{G} / \mathrm{L}$ by the addition of Platelet-Poor Plasma (PPP) obtained by centrifugation of the remaining blood at $1750 \mathrm{~g}$ for $10 \mathrm{~min}$ at $20^{\circ} \mathrm{C}$. Platelet- depleted Plasma (PDP) was obtained from PPP centrifuged at $13000 \mathrm{~g}$ for $30 \mathrm{~min}$ at $4^{\circ} \mathrm{C}$. PDP was immediately frozen at $-80^{\circ} \mathrm{C}$ and thawed $15 \mathrm{~min}$ at $37^{\circ} \mathrm{C}$ when needed.

\section{Thrombin generation}

CAT was performed with PRP and PDP as well, as described in [10]. Measurements were carried out in 96well circular bottom microtiter polypropylene plates (Greiner). Coagulation was initiated with 0.3 (PRP and PDP), 1 or $5 \mathrm{pM}$ (PDP only, for practical reasons) recombinant human tissue factor (TF) reagent $\left(\right.$ Innovin ${ }^{\circledR}$, Dade Behring), and, when PDP was studied, in the presence of $4 \mu \mathrm{M}$ phospholipid vesicles: phosphatidylcholine (PC)/ phosphatidylserine (PS)/ phosphatidylethanolamine (PE); (PC/PS/PE, 60/20/20, mole \%).

\section{Statistical analysis}

Data are presented as median (min-max). Wilcoxon test was used to compare before and after surgery coagulation parameters (platelet count, prothrombin time, activated partial thromboplastin time (aPTT), fibrinogen, antithrombin, and prothrombin) as well as the decrease in ETP (before /after CBP) with both PRP and PDP at different TF concentrations. ETP values obtained by the different preparations were compared using a KruskallWallis test both before and after surgery.

\section{Results}

Surgery was uneventful as indicated by the following parameters: CPB duration (min): 64 (48-118); cross clamp time (min): 52 (25-90); 24 h blood loss (mL): 385 (170-750). Coagulation parameters measured before and after surgery are shown in Table 1.

Heparin neutralization with protamine was checked with thrombin time. No patient was transfused before blood sampling. Tranexamic acid was routinely used. No patient was transfused before the second blood sampling.

Thrombin generation was studied in vitro by CAT using citrated plasma in presence or absence of platelets.

As expected from the design of our study, no patient had abnormal bleeding, the maximal volume collected
Table 1 Patients' coagulation parameters before and after surgery

\begin{tabular}{lcc}
\hline & Pre-operatively & Post-operatively \\
\hline Platelet count (G/L) & $240(109-337)$ & $122(67-201)$ \\
\hline prothrombin time (sec) & $12.9(12.9-13.9)$ & $16.5(14.8-19.7)$ \\
\hline aPTT (sec) & $33(29-59)$ & $43(34-58)$ \\
\hline Fibrinogen (g/L) & $4(3.4-4.6)$ & $2.3(1.3-2.7)$ \\
\hline Prothrombin (\%) & $85.5(55-95)$ & $57.5(30-73)$ \\
\hline Antithrombin (\%) & $97.5(70-108)$ & $64(44-77)$ \\
\hline
\end{tabular}

Data are reported as median (min-max) of 10 patients. All decreases in platelet count, prothrombin time, aPT, fibrinogen, prothrombin and antithrombin are statistically significant. $p<0.05$ when comparing post-operating parameter to pre-operating parameter. CPB: cardiopulmonary bypass, aPTT: activated partial thromboplastin time.

during the first 24 hours being $750 \mathrm{~mL}$, and the lowest post-CPB ETP we observed, was greater than $1000 \mathrm{nM}$. min (with PRP).

Comparison of ETP from different experimental conditions by Kruskall-Wallis test did not show any significant difference before surgery $(p=0.0674)$. However after surgery ETP values were significantly different among preparations $(\mathrm{p}=0.0009)$. Therefore we chose to compare ETP values before and after surgery for each preparation separately.

There was a statistically significant (Wilcoxon test) decrease in ETP (before /after CBP) with both PRP and PDP regardless the TF concentration. Our main finding was that CPB-induced coagulopathy was differently appreciated depending on the presence or absence of platelets. The percentage of variation between pre- and post-operative values of ETP was much lower with PRP $(-3.9 \%)$ than with PDP $(-39.6 \%)$ compared with a statistical Wilcoxon test (Table 2).

The ETP pre-post variations observed with PRP were statistically significantly different compared to PDP in the presence of $0.3 \mathrm{pM}$ TF, but not to PDP in the presence of 1 and $5 \mathrm{pM}$, probably because of a greater variations between the individual values. In our hands, 0.3 $\mathrm{pM}$ is the lowest TF concentration allowing reliable observation of thrombin generation and fully taking into account the 'intrinsic' tenase (anti-haemophilic factors).

\section{Discussion}

Our results show that coagulopathy associated to $\mathrm{CPB}$ was observed, in vitro, not only with PPP but also with PRP. Our main new observation is that this coagulopathy was differently appreciated depending on the presence or absence of platelets.

The number of enrolled subjects (10 patients recruited in this study) was estimated to allow us to document the actual extent of hypocoagulability and to compare the different experimental settings. 
Table 2 Thrombin generation before and after CPB with PRP and PDP (at three TF concentrations)

\begin{tabular}{llcc}
\hline & & ETP (nM.min) & Change (\%) \\
\cline { 2 - 4 } & Pre-operatively & Post-operatively & $-3.9(4 ;-26.1)$ \\
\hline PRP (0.3 pM TF) & $1505(1160-2464)$ & $1491(1087-2544)$ & $-39.6(13.9 ;-61.3)$ \\
\hline PDP (0.3 pM TF) & $1468(1032-1913)$ & $970(500-1323)$ & $-24.4(18.7 ;-52.7)$ \\
\hline PDP (1 pM TF) & $1560(1255-1928)$ & $1083(742-1990)$ & $-30,5(28 ;-52.7)$ \\
\hline PDP (5 pM TF) & $1723(1338-2121)$ & $1189(810-2335)$ & \\
\hline
\end{tabular}

Data are reported as median (min-max) of at least 8 patients (10 patients enrolled- a few missing data for technical reasons). All decreases in ETP are statistically significant. $p<0.05$ when comparing ETP change with PRP to those with PDP in presence of 0.3 pM TF. ETP: Endogenous Thrombin Potential. PDP: platelet-depleted plasma, PRP: platelet-rich plasma, TF: recombinant human tissue factor.

As indicated above, no patient had abnormal bleeding. The lowest post-CPB ETP we observed, was greater than 1000 nM.min (with PRP); in one of our previous works [5], we reported the normal ETP to be $1579 \pm 359 \mathrm{nM}$. min and for mild heamophiliacs the average value was $1060 \pm 450$ nM.min.

Our results concerning the decrease in ETP values with PDP after CPB were in agreement with previous studies $[7,8]$ studied only with PPP and in presence of very higher TF concentration $(20 \mathrm{pM})$ used in [7]. This suggests that the observed coagulopathy after $\mathrm{CPB}$ was not associated with the amplification phase of thrombin generation which depends on the TF concentration and is rather associated with the global phenomenon of thrombin generation.

Moreover, we did not find any consistent change in the duration of the initiation phase (by contrast to what has been reported in [8] "data not shown"). In addition, we have shown that this decrease in ETP values occurs also with PRP after CPB. Several mechanisms have been implicated in the haemostatic defects observed after CPB: consumption of coagulation factors and platelets, dilution, activation of fibrinolysis and transient platelet function defect [2,11-15].

Although we have not studied platelet function in the PRP of our patients, many other studies have described that platelet dysfunction is thought to result from many factors, such as contact with the synthetic surfaces of the extracorporeal circuit and hypothermia associated with bypass [2,11,12]. Many alterations have been reported, including ? granule depletion and membrane glycoprotein decreases such as GPIIbIIIa [2,11,12]. No major alteration of procoagulant properties of platelets has been reported however, which is consistent with the slight decrease in ETP we observed with patients' PRP. This explanation is supported by the observation of Reverter et al. [16] that a platelet dysfunction in patients of Glanzmann syndrome who lack GP IIb/IIIa on platelet surfaces results in a moderate impact on thrombin generation (21\% less than normal platelets). They have also shown a moderate deficiency in thrombin generation (25\%) in the presence of antibodies against GPIIbIIIa. Although this effect has not been described directly in the context of $\mathrm{CPB}$, a significant decrease in the amount of membrane antigen for glycoproteins as IIb, and IIIa on circulating platelets following CPB has been reported [2]). In addition, the depletion of ? granules, which contain GPIIbIIIa, has been reported in the context of CPB $[2,12]$. In addition, we suggest that other procoagulant actors would be present in PRP and not in PDP, capable of compensating plasma coagulopathy. This hypothesis is supported by the finding that procoagulant microparticles are generated during $\mathrm{CPB}$, released not only from platelets but also from erythrocytes, monocytes, granulocytes and other cells, especially into pericardial blood [17]. Thus, these microparticles, eliminated with the centrifugation used to prepare PDP, might play, in vitro, a procoagulant role in coagulation with PRP, but not with PDP. Whatever the reason, it appears that a plasma hemostatic defect can be partly compensated by platelets [18]. However, the relation between these measurements, in vitro, and the clotting process, in vivo, is unknown.

In conclusion, our findings highlight that the experimental conditions are crucial in the study of in vitro thrombin generation in the context of $\mathrm{CPB}$, the presence of platelets and microparticles being associated with a distinct pattern.

\section{Limitations of this study}

Other experimental conditions for CAT had to be taken into account, for example, platelet count, the use of corn trypsin inhibitor (CTI) - to prevent artificial contact phase activation -, the concentration of TF; and the activated protein $\mathrm{C}$ system which would improve the relation to clinical outcome.

\section{Abbreviations}

CPB: Cardiopulmonary bypass; CAT: Calibrated automated thrombography; ETP: Endogenous thrombin potential; PRP: Platelet-rich plasma; PPP: Plateletpoor plasma; PDP: Platelet-depleted plasma; PC: Phosphatidylcholine; PS: Phosphatidylserine; TF: Recombinant human tissue factor; aPTT: Activated partial thromboplastin time; CTI: Corn trypsin inhibitor.

\section{Competing interests}

The authors declare that they have no competing interests.

Authors' contributions

All authors read and approved the final manuscript. 


\section{Author details}

'Laboratoire d'Hématologie et Institut Cardiovasculaire Nancy, Centre Hospitalier Universitaire, Nancy, France. ${ }^{2}$ Inserm U961, Nancy Université, Nancy, France. ${ }^{3}$ EFS Lorraine Champagne, Nancy, France. ${ }^{4}$ Haematology Laboratory, CHU Nancy, Rue du Morvan, 54511 Vandoeuvre les Nancy Cedex, France.

Received: 12 October 2011 Accepted: 2 August 2012

Published: 21 August 2012

\section{References}

1. Bevan DH: Cardiac bypass haemostasis: putting blood through the mill. Br J Haemato 1999, I104:208-219.

2. Woodman RC, Harker LA: Bleeding complications associated with cardiopulmonary bypass. Blood 1990, 76:1680-97.

3. Lecompte T, Hacquard M, Carteaux JP: Eptacog-alpha (activated) aka human clotting factor VII recombinant and activated, in cardiac surgery with cardiopulmonary by pass: where do we stand in 2006? ITBM-RBM 2006, 27:S35-S39.

4. Weerwind PW, Lindhout T, Caberg NE, De Jong DS: Thrombin generation during cardiopulmonary bypass: the possible role of retransfusion of blood aspirated from the surgical field. Thromb J 2003, 1(1):3.

5. Trossaërt M, Regnault $V$, Sigaud $M$, Boisseau P, Fressinaud $E$, Lecompte $T$ : Mild hemophilia A with factor VIII assay discrepancy: using thrombin generation assay to assess the bleeding phenotype. J Thromb Haemost 2008, 6(3):486-493.

6. Schols SE, Feijge MA, Lancé MD, Hamulyák K, ten Cate H, Heemskerk JW van Pampus EC: Impaired thrombin generation and fibrin clot formation in patients with dilutional coagulopathy during major surgery. Thromb Haemost 2010, 103:318-328.

7. Solomon C, Rahe-Meyer N, Sørensen B: Fibrin formation is more impaired than thrombin generation and platelets immediately following cardiac surgery. Thromb Res 2011, 128:277-827.

8. Coakley M, Hall JE, Evans C, Duff E, Billing V, Yang L, McPherson D, Stephens E, Macartney N, Wilkes AR, Collins PW: Assessment of thrombin generation measured before and after cardiopulmonary bypass surgery and its association with postoperative bleeding. J Thromb Haemost 2011, 9:282-292.

9. The Subcommittee on Control of Anticoagulation of the SSC of the ISTH: Towards a recommendation for the standardization of the measurement of platelet-dependent thrombin generation. J Thromb Haemost 2011, 9:1859-61.

10. Hemker HC, Giesen P, Al Dieri R, Regnault V, de Smedt E, Wagenvoord R, Lecompte S, Béguin S: Calibrated automated thrombin generation measurement in clotting plasma. Pathophysiol Haemost Thromb 2003, 33(1):4-15.

11. Flaujac C, Pouard P, Boutouyrie P, Emmerich J, Bachelot-Loza C, Lasne D: Platelet dysfunction after normothermic cardiopulmonary bypass in children: effect of high-dose aprotonin. Thromb Haemost 2007, 98:385-391.

12. Pumphrey CW, Dawes J: Platelet alpha granule depletion: findings in patients with prosthetic heart valves and following cardiopulmonary bypass surgery. Thromb Res 1983, 30:257-64.

13. Lecompte T, Carteaux JP, Regnault V, de Maistre E, Collet JY, JP V: Is it possible and worth to use another anticoagulant than (unfractionated) heparin during cardiopulmonary bypass for cardiac surgery? ITBM-RBM 2003, 24:S35-S39.

14. Blome M, Isgro F, Kiessling AH, Skuras J, Haubelt H, Hellstern P, Saggau W: Relationship between factor XIII activity, fibrinogen, haemostasis screening tests and postoperative bleeding in cardiopulmonary bypass surgery. Thromb Haemost 2005, 93:1101-7.

15. Prisco D, Paniccia R: Point-of-care: testing of hemostasis in cardiac surgery. Thromb J 2003, 1(1):1.

16. Reverter JC, Béguin S, Kessels H, Kumar R, Hemker HC, Coller BS: Inhibition of platelet-mediated, tissue factor-induced thrombin generation by the mouse/human chimeric $7 \mathrm{e} 3$ antibody. potential implications for the effect of c7E3 Fab treatment on acute thrombosis and "Clinical Restenosis". J Clin Invest 1996, 98:863-874.
17. Nieuwland R, Berckmans RJ, Rotteveel-Eijkman RC, Maquelin KN, Roozendaal KJ, Jansen PG, ten Have K, Eijsman L, Hack CE, Sturk A: Cell-derived microparticles generated in patients during cardiopulmonary bypass are highly procoagulant. Circulation 1997, 96:3534-41.

18. Schols SE, Feijge MA, Lancé MD, Hamulyák K, ten Cate H, Heemskerk JW, van Pampus EC: Effects of plasma dilution on tissue-factor-induced thrombin generation and thromboelastography partly compensating role of platelets. Transfusion 2008, 48:2384-2394.

doi:10.1186/1477-9560-10-15

Cite this article as: Said et al:: Platelet-dependent thrombography gives a distinct pattern of in vitro thrombin generation after surgery with cardio-pulmonary bypass: potential implications. Thrombosis Journal 2012 10:15.

\section{Submit your next manuscript to BioMed Central and take full advantage of:}

- Convenient online submission

- Thorough peer review

- No space constraints or color figure charges

- Immediate publication on acceptance

- Inclusion in PubMed, CAS, Scopus and Google Scholar

- Research which is freely available for redistribution 